\title{
Habitação Social em São Paulo: \\ Alternativa em Análise
}

\section{Housing for Low Income Families in São Paulo: an Alternative in Analysis}

\author{
Junker de Assis Grassiotto ${ }^{1}$; Maria Luiza Fava Grassiotto ${ }^{2}$
}

\begin{abstract}
Resumo
O processo de urbanização no Brasil fez com que mais de 119 milhões de pessoas passassem a morar nas cidades, gerando a partir de meados do século passado, a necessidade de aproximadamente 26 milhões de novas moradias. nas metrópoles, os loteamentos e as casas (executadas por autoconstrução), em sua imensa maioria, surgiram clandestinamente. por meio do bnh, no período 1964-86, o governo promoveu o financiamento de 4 milhões de unidades, um número expressivo porém pequeno, diante da dimensão do problema. depois disso não se teve nova definição de projeto duradouro, diante das sucessivas crises econômicas. $\mathrm{O}$ atual momento econômico, de alto endividamento externo e interno, não permite vislumbrar, num futuro próximo, perspectivas alvissareiras de recursos fartos, muito pelo contrário. Dentro desse contexto, o presente artigo traça um perfil da casa autoconstruída e do autoconstrutor, pois parte da premissa que diante da escassez de meios, a alternativa para viabilizar moradia aos menos favorecidos é a autoconstrução individualizada ou coletivizada. tecem-se, então, considerações relativas àquela que envolve o maior número de pessoas, ou seja a primeira, comentando-se possíveis diretrizes a serem seguidas em relação à aplicação de recursos e à elaboração de projetos com envolvimento dos usuários. Ao final, encontra-se particularizada, uma alternativa para a construção de moradias populares, empregando blocos de concreto empilhados a seco, criada por um dos autores, apresentando-se inclusive detalhes de execução. na conclusão estão colocadas as vantagens do novo sistema.
\end{abstract}

Palavras-Chave: Habitação social, desenvolvimento urbano, autoconstrução.

\begin{abstract}
The urbanization process in Brazil has caused 119 million people to live in the cities, creating the necessity of nearly 26 million new residences, from the middle of the last century on. In the metropolis, most of the houses (self-help constructed) arose clandestinely. Through BNH (Banco Nacional da Habitação), in the period of 1964-86 the government fostered the financing of 4 million units, a significant number, yet a small one, due to the dimension of the problem. After this, there was no new definition of a durable project, due to successive economical crises. The economical moment of high internal and external indebtedness does not make it possible to expect, in near future, auspicious perspectives of full resources, on the contrary. In this context, the present article draws up a profile of the self-help constructed house as well as of the self-help constructor, because it is based on the premise that, due to the shortage of resources, the alternative to make housing viable to the less favored ones, is the self-help construction, individual or collective. Considerations related to the first one, which involves a larger number of persons are taken into account, commenting on possible alternatives to be followed in relation to the application of resources and to the elaboration of projects involving users. At the end, a particular solution of housing for income families is emphasized, using dry-stack concrete blocks presenting several construction details. Also, the advantages of the new system are outlined.
\end{abstract}

Keywords:Housing, low-income families housing, urban development, self-help construction.

\footnotetext{
1 Engenheiro civil, Mestre em Arquitetura e Urbanismo pelo MINTER FAU/USP - DAU/UEL, pesquisador do NUTAU (Núcleo de Tecnologia em Arquitetura e Urbanismo da FAU/USP), doutorando pela FAU/USP. E-mail: grassiotto@uel.br

2 Arquiteta, professora e pesquisadora da UEL, Mestre em Arquitetura e Urbanismo pelo MINTER FAU/USP - DAU/UEL, pesquisadora do NUTAU (Núcleo de Tecnologia em Arquitetura e Urbanismo da FAU/USP), doutoranda pela FAU/USP. Email: grassiotto@uel.br
} 


\section{Introdução}

Vive-se no Brasil uma situação de desequilíbrio urbano, devido ao forte processo migratório que já vem ocorrendo há muito tempo e acentuou-se a partir dos anos sessenta do século passado.

Num crescimento urbano tão desenfreado, praticamente fica impossível equacionar a construção de novos espaços para moradia em concomitância com seu desenvolvimento. As pessoas que chegam precisam de soluções imediatas quanto à infra estrutura urbana e moradia, o que é impossível ser provido pelo poder público no tempo exigido. Então cada pessoa ou família procura encontrar um meio de se instalar. Assim surgem as favelas do terceiro mundo, pelo inchamento das cidades. Nos países pobres, a carência de meios é gritante e os recursos públicos fortemente limitados, fazendo com que os governos fiquem impotentes diante da magnitude dos problemas. Tentam fazer o possível, mas não conseguem muito. Na verdade o que se deve admitir é que as soluções acabam vindo a longo prazo, dependentes em grande parte da cessação ou pelo menos diminuição do processo imigratório.

No momento, o país vive uma forte crise econômica. As dívidas interna e externa praticamente impedem que se façam novos investimentos. Sendo assim, para se dar andamento a programas de desfavelamento, se faz necessário o emprego de criatividade, tecnologia, meios de aglutinação e liderança.

As pessoas têm grande capacidade para encontrar soluções. A autoconstrução é uma demonstração cabal disso. Acontece que o autoconstrutor não dispõe de conhecimento suficiente e essas obras acabam sendo executadas sem planejamento, com desperdícios e má qualidade.

No presente artigo se tenta, em poucas palavras, traçar o perfil do autoconstrutor e propor uma alternativa construtiva que exige um pouco mais de disciplina e tecnologia. A proposta se volta para a região metropolitana de São Paulo, mas com certeza pode ser adequada a praticamente todas as outras regiões do país que enfrentam problemas semelhantes. Como o assunto está voltado para a construção, ficaria para o poder público (municipal, estadual e federal) a questão da infra estrutura, que, em termos individuais, não pode ser resolvida.

\section{Traçando o Perfil da Casa Autoconstruída e do Autoconstrutor}

Quando se procura ordenar as possibilidades construtivas adotadas para viabilizar moradia para as classes menos favorecidas verifica-se que as alternativas basicamente são: a) autoconstrução individualizada; b) autoconstrução coletivizada (mutirão); c) construção de conjuntos por terceiros (empresas) financiados.

A autoconstrução individualizada, que responde pela maioria das habitações no país, de um modo geral abrange dois tipos: 1) O primeiro, que aqui será denominado provisório, refere-se àquela casa feita com materiais improvisados por pessoas extremamente pobres, que não dispõem de qualquer recurso. Na verdade, constroem um simples abrigo com qualquer chapa que encontram fazendo a cobertura sempre sem nenhuma técnica. Este caso não poderia nem ser chamado de casa. Ao final, no entanto, a necessidade acaba por obrigar esses construtores a muitas vezes viverem nessas condições por longos períodos. Não há muito a dizer a respeito dessas construções a não ser que obrigatoriamente precisam ser substituídas. 2) $\mathrm{O}$ segundo, a autoconstrução individualizada propriamente dita, denomina aquela obra executada pelos futuros moradores e eventualmente alguns amigos, podendo parte do serviço ser contratada com terceiros. São casas, quase sempre em alvenaria, edificadas rudimentarmente ficando na maioria das vezes sem acabar, faltando revestimentos, cobertura, pisos ou outras partes. De um modo geral empregam baixíssima tecnologia e têm péssima qualidade.

A autoconstrução coletivizada é aquela executada em conjunto pelos futuros moradores, porém em regime de mutirão. De um modo geral o processo é 
encampado pela prefeitura municipal que coordena os projetos e a execução, dando gratuitamente assessoria técnica. Podem ser construídas unidades unifamiliares ou habitações coletivas (edifícios residenciais). O nível tecnológico empregado corresponde ao habitualmente encontrado nas obras executadas tradicionalmente pelas empresas, sem qualquer inovação, porém exige a responsabilidade de gerenciamento por terceiros, que são funcionários do próprio município ou pessoas contratadas para fazê-lo.

A construção de conjuntos por terceiros é aquela contratada através de entidades como as Companhias de Habitação, ou o próprio agente financeiro, por empreita, seguindo os métodos tradicionais. De modo geral, envolvem maiores custos finais prevendo Benefícios e Despesas Indiretas para as empresas executoras. Dentro desse esquema, as previsões de recursos da Caixa Econômica Federal para investimentos em 2002 foram os seguintes: 1) FGTS - R\$ 3,8 bilhões; 2) Programa de Arrendamento Residencial (PAR) - R \$ 1,2 bilhões; 3) Fundo de Assistência ao Trabalhador (FAT) - R \$ 1,0 bilhão; 4) Caixa Econômica Federal - R $\$ 1,5$ bilhão; 5) Orçamento da União - R \$ 0,7 bilhão. O total sendo da ordem de $\mathrm{R} \$ 8,2$ bilhões, pretendia atender a aproximadamente 460 mil mutuários. Em 2000 foram investidos R \$ 7,2 bilhões que financiaram $408 \mathrm{mil}$ mutuários. Entre 1995 e 2001, a CEF ensejou acesso à casa própria a 1,9 milhões de famílias, por meio da aplicação de R $\$ 27$ bilhões. Os dados acima citados se encontram no Boletim da Caixa, janeiro de 2002, que textualmente diz: "o país precisa, agora, é olhar com mais atenção para as famílias com renda inferior a três salários mínimos, que concentram $84 \%$ do déficit habitacional, estimado em 6,5 milhões de unidades".

Estabelecidas as alternativas construtivas, a seguir se pretende tecer algumas considerações em relação àquela que envolve o maior número de pessoas, ou seja a autoconstrução individualizada. Comumente, ao obterem a posse de um terreno urbano, as famílias de baixa renda sonham com a construção da moradia.
Para isso tomam a iniciativa isoladamente, contando, na maioria das vezes, somente com o conhecimento próprio ou de alguns amigos. Geralmente têm algum recurso, quase nunca suficiente para executar a obra por inteiro. A conclusão, quando acontece, demora muitos anos. As melhorias vão acontecendo em função das disponibilidades, esse é um dos maiores problemas, pois não se pode contar com um mínimo de planejamento. Eis a questão chave: se o autoconstrutor, pudesse partir de um projeto, empregando determinado sistema construtivo, adequado à sua realidade, com os mesmos recursos obteria resultados muitos melhores. Segundo Ferreira (1998, p.24):

$\mathrm{O}$ arquiteto Paulo Bruna comenta a corrente justificativa de que não se industrializa a construção habitacional no Brasil devido ao baixo poder aquisitivo da população carente de moradia: "Nestas condições, afirma-se que os métodos tradicionais que fazem largo uso da mão de obra barata são ainda os que proporcionam os custos mais baixos. Mas se ainda resta provar que os custos da construção são baixos e que estes decorrem exclusivamente do custo intrínseco da mão de obra, nós sabemos também a que preço de suor e lágrimas trabalha o pessoal de nossas obras". Ainda sobre a defesa do emprego de técnicas tradicionais, conclui: "efetivamente os preços da construção não são baixos, pelo contrário, são tão altos que impedem a uma larga percentagem da população urbana usufruir de habitações que contenham os requisitos mínimos de uma moradia, que estejam abastecidos de água, luz, esgoto e que se possa afirmar estejam integradas numa comunidade corretamente atendida pelos serviços de saúde, educação, abastecimento, transporte e recreação.

Para se propor um sistema construtivo, antes se faz necessário conhecer o que deseja o autoconstrutor. "No sentido de qualificar o projeto para a autoconstrução, a composição das variáveis deve levar ao que chamaremos aqui de as três liberdades" (SZUCS, 1995, p.83).

1. Liberdade para o usuário/construtor que intercederá ele próprio no projeto, satisfazendo suas necessidades funcionais e espaciais. 
2. Liberdade para o projetista que conceberá da maneira que lhe aprouver, à partir da oferta de materiais no mercado.

3. Liberdade para a indústria que produzirá componentes sem compromisso prévio com soluções pré-concebidas.

Ainda de acordo com a professora Szucs (1995, p.84-85), listam-se a seguir os requisitos que podem orientar o projeto autoconstrutivo.

1. Evolutividade - Oferecer um produto que responda de uma só vez a dois grupos de preocupações: a) as necessidades imediatas do cliente (quanto ao número de membros e às expectativas da família) e mediatas (como mudanças familiares ou necessidades funcionais); b) as características formais, culturais e sócio-econômicas da população alvo.

2. Economia - Oferecer um produto otimizado no projeto, no material despendido e no uso do solo, reduzindo as perdas e portanto o custo global da obra. Oferecer um produto confortável, compatível com um custo acessível à população alvo, possibilitando por conseguinte o crescimento da unidade de acordo com as condições da família sem com isso desqualificar as partes já construídas. Oferecer um produto de manutenção facilitada e de baixo custo.

3. Simplicidade construtiva - Possibilitar um máximo de produtividade reduzindo o tempo de obra e permitindo uma pronta utilização da unidade. Ter uma dependência mínima em relação à indústria ou ao setor da construção civil, reduzindo o mais possível o trabalho de terceiros. Oferecer um produto cuja produção possa ser implementada pelos próprios clientes, reduzindo ou eliminando os custos de mão de obra.

$$
\text { Conforme Serra (2000, p.503): }
$$

Os autoconstrutores respondem por mais de $55 \%$ do consumo de cimento brasileiro e mais do que $50 \%$ do mercado de materiais de construção [...]. São os maiores construtores de casa no Brasil. Porém a eficiência e eficácia destes construtores são muito baixas porque eles não têm conhecimento tecnológico suficiente para fazer suas casas.

Em 1994 o NUTAU, Núcleo de Pesquisa em Tecnologia da Arquitetura e Urbanismo da Universidade de São Paulo, pesquisou junto aos autoconstrutores, pequenas indústrias de préfabricados e lojas de materiais de construção para compreender o sistema de produção de casas construídas pelos seus proprietários e constatou que: 1) $[\ldots]$;2) as casas executadas pelos autoconstrutores têm má performance em conforto e durabilidade; 3 ) [...]; 4) a perda de material está sempre presente; 5) existe uma falta de orientação técnica para esses construtores (SERRA, 2000, p.503).

Taschner (1998, p.181) comenta:

O material predominante que compõe as paredes externas dos barracos não mais é a madeira: 50,5\% das casas são de alvenaria. A mudança neste particular aspecto foi a mais impressionante: acinzentaram-se as favelas paulistanas. $\mathrm{O}$ bloco de concreto impera como solução construtiva em 25,31\% das casas. A madeira que era, em $1973 \mathrm{e} \mathrm{em}$ 1980, material único ou nitidamente majoritário, vai aparecer em 1987 em cerca de 40\% das unidades, evidenciando nítida mudança em relação a 1980 (93,90\% das unidades possuíam a vedação externa em madeira nova e/ou usada.

Talvez no período tenha havido algum ganho de renda permitindo que as construções melhorassem de qualidade, porém com certeza a madeira subiu muito de preço, pelo processo de escassez que foi se acentuando com o passar dos anos. Hoje dificilmente alguém construiria uma casa de madeira. O bloco de concreto com certeza é a melhor opção e a mais barata. Segundo Taschner (1998, p.182):

O uso de madeira para a cobertura diminui enormemente. $\mathrm{O}$ telhado é predominantemente de cimento-amianto (84,10\% das casas em 1987), opção determinada, sobretudo, pelo seu menor custo final. Mas surpreende a introdução da laje pré-moldada, usada em 7\% das casas em 1987. Como já foi dito o uso de laje permite uma ampliação vertical da moradia que resulta num adensamento (que já está se verificando). Quanto ao piso, diminui consideravelmente a percentagem de moradias com terra batida (de 46,3\% em 1973 para 17,7\% em 1980e 7,43\% em 1987), evidenciando uma melhoria sanitária 
considerável. Utiliza-se majoritariamente o piso cimentado (33\% em 1973, 81\% em 1980 e $87 \%$ em 1987). As condições sanitárias dentro do domicílio apresentaram sensível melhoria: em 1973, 65,8\% das casas em favela não tinham banheiro e/ou utilizavam banheiro coletivo. Este percentual desce para 38,5\% em 1980 e para $10,9 \%$ em 1987, quando se observou que $70,5 \%$ das moradias utilizavam banheiro individual interno. $\mathrm{O}$ maior adensamento observado na unidade domiciliar e nas favelas nem sempre foi acompanhado por melhoria em todos os serviços urbanos. A ausência de infra-estrutura sanitária continua dramática, com $56 \%$ dos domicílios lançando dejetos ao ar livre e/ou diretamente a córregos.

A população favelada é mais jovem que a população municipal como um todo: cerca de $46 \%$ dos moradores dos aglomerados favelados têm até 14 anos. Para o município como um todo essa proporção era, em 1980, 29,9\%. Quanto à procedência, em 1980, $60,8 \%$ da população favelada era constituída de não naturais do município de São Paulo. Considerandose o subconjunto de chefes de família, essa porcentagem sobe para $88,4 \%$. A favela tampouco é etapa provisória de chegada à metrópole, trampolim para a integração na vida urbana, pois pouco mais de $1 \%$ dos chefes entrevistados aqui está a menos de 1 ano. Ao contrário, $74 \%$ deles está na cidade há mais de 10 anos (TASCHNER, 1998, p.184).

Em 1987, acompanhando a terceirização da cidade, $47 \%$ dos chefes trabalham no setor terciário. A distinção entre o chefe favelado e o restante da classe trabalhadora está no fato dele ter, predominantemente, ocupação manual semi ou não especializada. Os dados de escolaridade completam esse perfil sócio-econômico: $18 \%$ são analfabetos e apenas $43 \%$ fizeram até a $4^{\text {a }}$ série do $1^{\circ}$ grau, mesmo incompleta, o que fornece um quadro de $57 \%$ dos chefes categorizados como analfabetos funcionais (TASCHNER, 1998, p.185).

Fica assim estabelecido o perfil da casa autoconstruída e do autoconstrutor, para quem se pretende a seguir apresentar uma proposta alternativa de obra.

\section{Particularizando uma das Alternativas para a Construção de Moradias Populares}

Os blocos de concreto vêm sendo usados industrialmente em muitos países desde o início do século XX. Atualmente é um dos produtos mais conhecidos no campo da construção civil e, no Brasil, a cada dia que passa, mais avança a sua utilização, principalmente na cidade de São Paulo, onde já é considerado um material tradicional.

Especificamente em relação ao sistema construtivo apresentado no presente artigo, se partiu de um outro conceito, estabelecido por Gallegos (1989, p.139), fundamental no desenvolvimento dos estudos e adequado aos objetivos pretendidos:

As unidades empilháveis não requerem ser fabricadas com mais precisão dimensional do que as unidades convencionais de boa qualidade. Dado que é impossível produzir contínua e sistematicamente unidades idênticas à unidade nominal, sempre se haverá de contar com meios para assumir as diferenças no sistema construtivo. O método tradicional, porém não único para isto, consiste no uso de pequenas cunhas, normalmente de madeira, recuperáveis ou não, que permitem reorientar a direção da parede assim que esta comece a perder alinhamento ou prumo. Aceitado o fato de que se requer algum tipo de alinhamento, resulta irrelevante perseguir precisões inalcansáveis a um custo muito alto, quando a solução está simplesmente em um detalhe do sistema construtivo.

Evidentemente esta linha de raciocínio só pode ser considerada como correta se o objetivo for construir paredes de pequena altura, ou seja, da ordem de aproximadamente três metros. Para grandes alturas como cinco metros ou mais a precisão das medidas das unidades com certeza passa a ser muito mais importante em termos relativos.

A figura 1 apresenta os três elementos componentes da família de blocos de concreto para assentamento a seco, criada pelo autor. Como se pode notar, são peças de um módulo $15 \times 15$ x 15 $\mathrm{cm}$, de dois módulos $15 \times 15 \times 30 \mathrm{~cm}$ e de quatro módulos 15 x $15 \times 45 \mathrm{~cm}$. Essa última em forma de $\mathrm{T}$ invertido, tem a altura central de $30 \mathrm{~cm}$.

A figura 2 mostra um trecho de parede que ilustra perfeitamente a regra fundamental, única e obrigatória, a ser sempre obedecida no processo de 
empilhamento: "Os blocos $\mathrm{T}$, referenciais, de quatro módulos, devem sempre ser empilhados invertidos, com a primeira fiada sendo constituída alternativamente por ele e por outro de um módulo". O descumprimento dessa regra elimina o travamento longitudinal nas fiadas superiores, pois acontece a diminuição da estabilidade, principalmente durante a construção de paredes. $\mathrm{O}$ sistema perde a razão de ser.
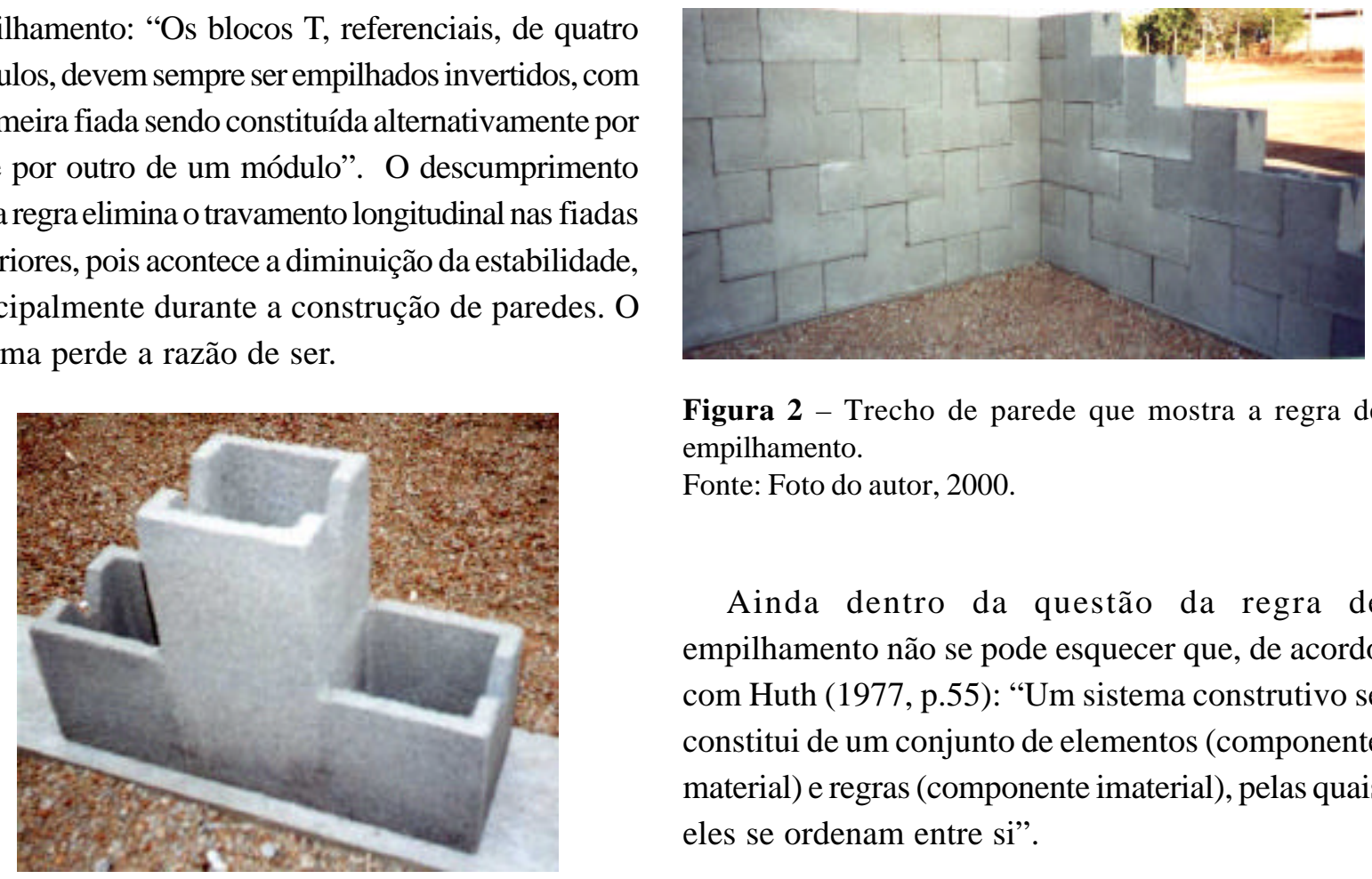

Figura 2 - Trecho de parede que mostra a regra de empilhamento.

Fonte: Foto do autor, 2000.

Ainda dentro da questão da regra de empilhamento não se pode esquecer que, de acordo com Huth (1977, p.55): "Um sistema construtivo se constitui de um conjunto de elementos (componente material) e regras (componente imaterial), pelas quais eles se ordenam entre si”.

Cabe salientar, nesta introdução, que o sistema
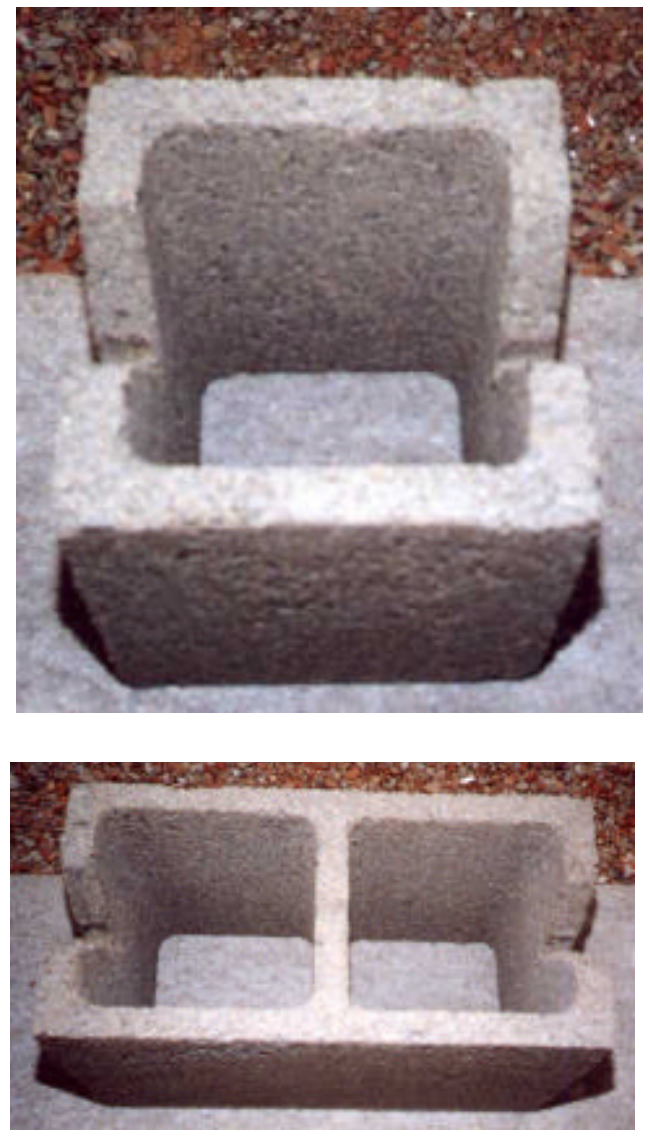
criado se destina, no presente momento, à execução de pequenas obras com até dois pavimentos, dentro, de um certo modo, do espírito idealizado por Gallegos. Cabe aqui antecipar que em função do grauteamento, que pode ser de até $100 \%$, esse limite de pavimentos deixa de ter sentido. Nestas condições se pensaria em edifícios com vários pavimentos, desde que obedecidas as normas e condições de cálculo.

Finalmente, cabe ainda informar que quanto ao processo de fabricação, no que se refere a equipamentos e suas modificações, maiores dados se encontram no texto do autor apresentado como dissertação de mestrado (GRASSIOTTO, 2000). O mesmo se deve dizer quanto a aspectos relativos a conforto térmico, conforto acústico e resistência ao fogo.

A seguir se apresenta um protótipo com $56,04 \mathrm{~m}^{2}$ de área, um escritório, muito semelhante a uma casa com dois dormitórios (a diferença está somente na eliminação de uma parede que separaria a sala de um dos dormitórios). As figuras 3 e 4 mostram a

Figura 1 - A família de blocos para empilhamento a seco. planta e o corte do projeto básico.

Fonte: Foto do autor, 2000. 
Adotou-se fundação em sapata corrida, função das características do solo e das baixas cargas atuantes. A laje de cobertura escolhida foi a do tipo maciça, pois optou-se por deixá-la aparente internamente, usando externamente uma camada de impermeabilização simples, que proporcionou um menor custo final (de um modo geral esta solução é muito usada pelo autoconstrutor, daí em parte a opção feita). A figura 5 mostra alguns aspectos da obra em execução, salientando-se os seguintes comentários:

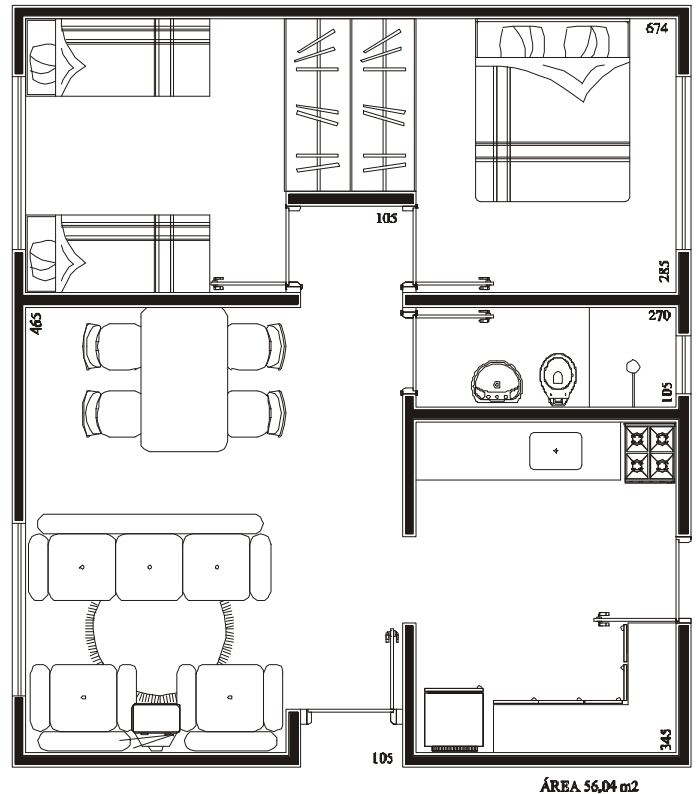

Figura 3 -Planta do projeto básico. REA 56,04 m:2 Fonte: Projeto do autor, 2000.

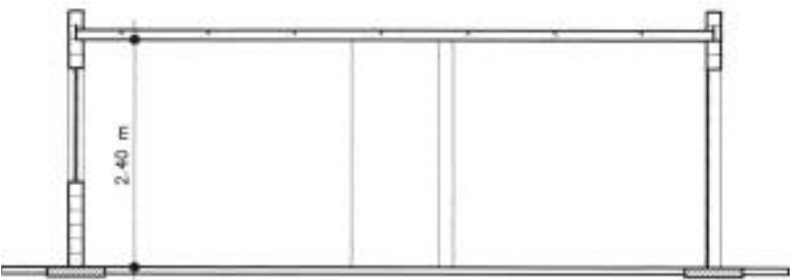

Figura 4 - Corte do projeto básico. Fonte: Projeto do autor, 2000.

1. antes de começar o empilhamento, a sapata ou viga que receberá os blocos precisa estar perfeitamente nivelada. A primeira fiada de blocos é assentada sobre uma fina camada de areia, da ordem de $2 \mathrm{~mm}$, que funciona como auxiliar na correção de eventuais pequenos defeitos;
2. o prumo e nível das paredes é obtido por meio do uso de galgas (réguas com pequenos pregos espaçados a cada $15 \mathrm{~cm}$ ). Dessa maneira extremamente simples, pode-se empilhar e acompanhar o desempenho das paredes conforme vão subindo. Se começam a sair do prumo, aplicam-se cunhas de madeira antes de prosseguir;

3. quando a parede chega à meia altura, cerca de 1,35 ou 1,50 m neste caso, o empilhamento é interrompido e feito o andaime, seguindo-se então o grauteamento parcial dos furos, que nunca pode deixar a face superior dos blocos niveladas, para efeito de continuidade (o graute deve chegar somente até a meia altura do último furo);

4. a partir daí segue-se com o empilhamento até o final, ficando a parede em condições de receber a laje, conforme mostra a figura 6 . O esquema de montagem da laje pode ser visto na figura 7 ;

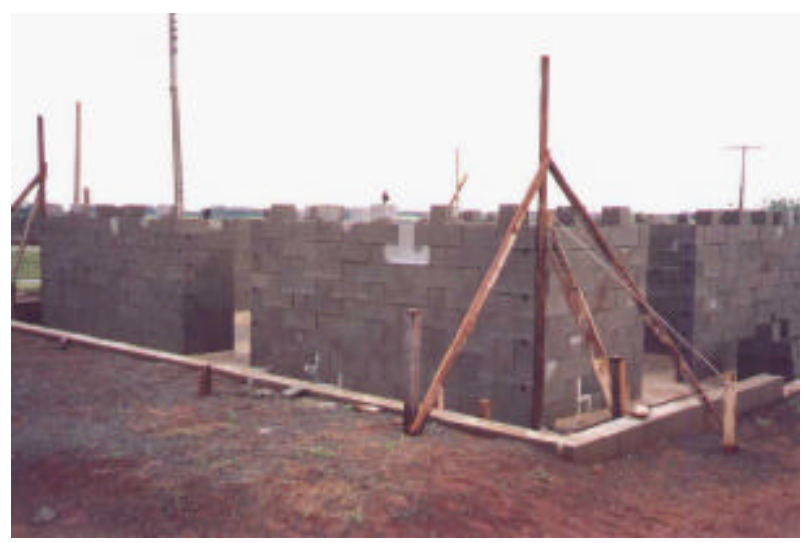

Figura 5 - A obra em execução mostrando as paredes a meia altura.

Fonte: Foto do autor, 2002.

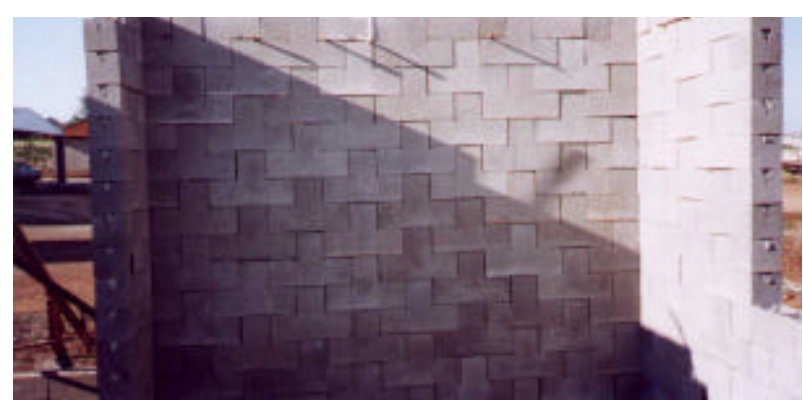

Figura 6 - As paredes prontas para receber a concretagem da laje de cobertura.

Fonte: Foto do autor, 2002. 


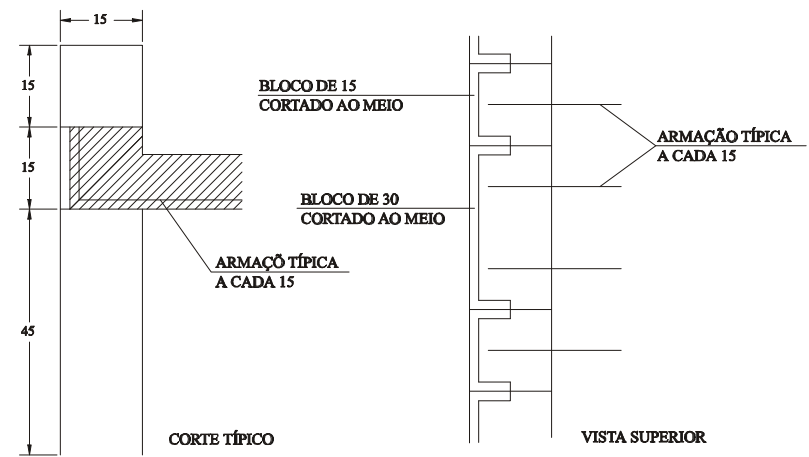

Figura 7 - Detalhe típico de execução de laje maciça. Fonte: Desenho do autor, 2000.

5. Não foi encontrado um filtro para a operação pedida.| incorporado *]as juntas são tomadas com um vedante líquido, flexível após endurecer. $\mathrm{Na}$ verdade o grauteamento garante uma total rigidez do conjunto, permitindo que no protótipo se venha a usar argamassa comum no rejuntamento;

6. a pintura então pode ser aplicada, tendo sido escolhida uma textura de baixo custo, tanto para a parte interna como para a externa, tendo ela demonstrado ter qualidade adequada às necessidades do projeto.

A figura 8 apresenta a fachada da obra concluída.

Mais alguns dados podem ser fornecidos:
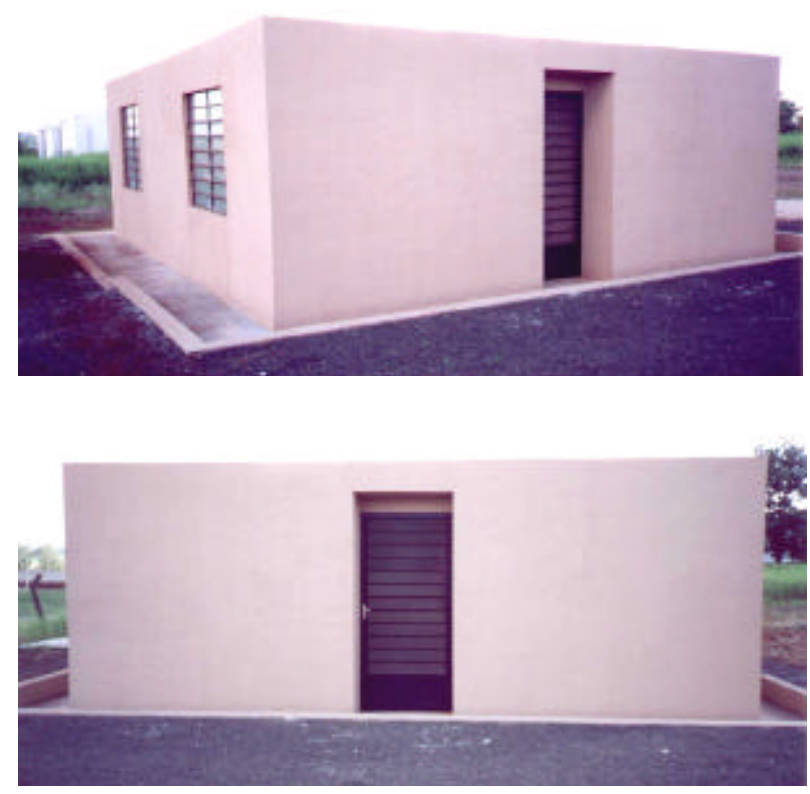

Figura 8 - Fachada principal da obra concluída. Fonte: Foto do autor, 2002.
1. as tubulações de instalações elétricas e hidráulicas (inclusive descida de águas pluviais) foram passadas pelos furos dos blocos, que têm dimensão mínima da ordem de $105 \mathrm{~mm}$ (Figura 9);

1. as esquadrias escolhidas são metálicas (portas e janelas), encomendadas sob medida, tendo elas recebido vidros martelados de $4 \mathrm{~mm}$;

3. adotou-se como piso, cerâmica esmaltada $30 \mathrm{x}$ $30 \mathrm{~cm}$;

4. o grauteamento, de acordo com o especificado pelo sistema, aconteceu a cada $60 \mathrm{~cm}$ (Figura 10). Este valor de espaçamento parece ser muito próximo, porém quando se pensa na obrigatoriedade de grautear todas as prumadas vizinhas às aberturas e também localizadas nos encontros de paredes, fica claro que o acréscimo é desprezível;

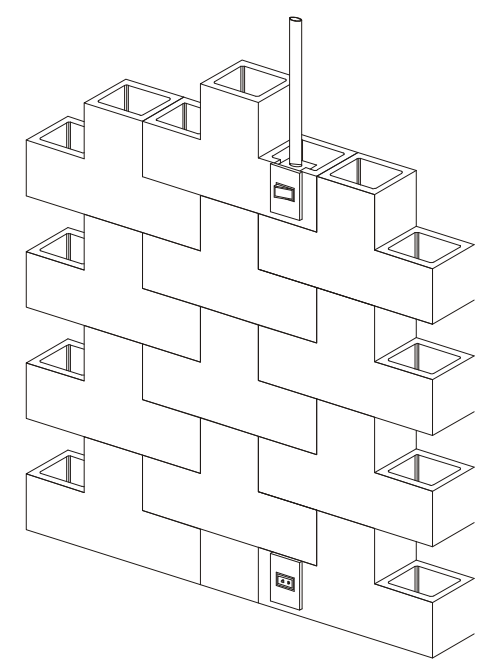

Figura 9 - Passagem de conduíte pelos furos dos blocos. Fonte: Desenho do autor, 2000.

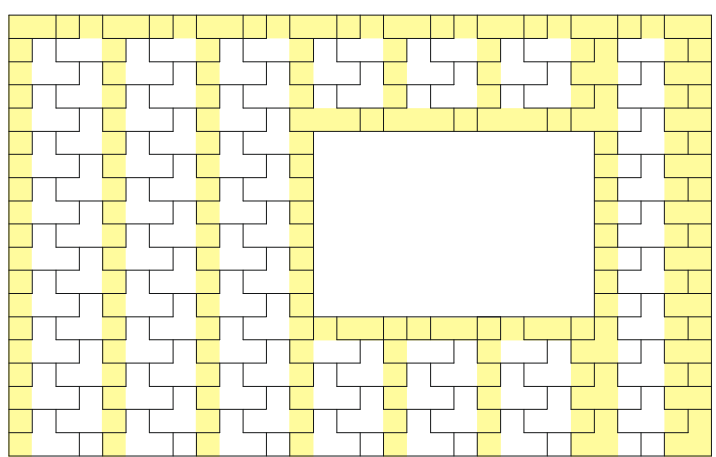

Figura 10 - Parede em blocos a seco com indicação das prumadas a serem grauteadas.

Fonte: Desenho do autor, 2000. 
5. não se usou qualquer ferragem vertical. Os reforços se destinaram a vencer os pequenos vãos das portas e janelas e a distribuir as cargas das lajes sobre as paredes.

Como pode ser observado na apresentação do sistema e do protótipo, as simplificações são por demais significativas destacando-se dentre elas:

6. o custo de fabricação dos blocos para assentamento a seco é basicamente o mesmo que o de fabricação dos blocos convencionais. Tendo em vista que cobrem uma maior área de parede, seu rendimento de produção acaba sendo maior;

7. o empilhamento demanda um tempo muito menor do que aquele que se gasta para executar uma parede com blocos convencionais, mesmo que ambos fiquem sem revestimento. Se comparado com a solução mais usada no país, ao empregar blocos a seco se está eliminando o assentamento convencional e os revestimentos que por si só exigem um tempo muito grande para a execução da parede;

8. ao se trabalhar com blocos a seco, resolve-se simultaneamente a preocupação estrutural. Um simples grauteamento de alguns furos garante estabilidade e resistência ao conjunto. Eliminase, praticamente, o uso de armação (exceto para vencer vãos de portas e janelas) e se acaba tendo uma simplificação ao lado de economia;

9. a mão de obra para assentamento a seco, sem dúvida, pode ser menos qualificada do que a usada em outros sistemas e também em menor quantidade. Como se sabe, o revestimento de uma parede convencional nas duas faces demanda mais trabalho do que executar a parede propriamente dita e implica custos semelhantes;

10.do ponto de vista somente de custos, pode-se dizer que em termos de materiais uma parede cerâmica convencional fica mais barata do que uma parede em blocos. No entanto, quando se somam a esses valores o do assentamento, esta solução convencional se equipara ao preço da outra solução também convencional com blocos de concreto estruturais assentados com argamassa.
Usando blocos empilhados, em relação a esta última, ainda se ganha o diferencial da mão de obra que fica reduzida a, no máximo, cerca de metade da empregada numa parede com blocos assentados com argamassa.

O tratamento desenvolvido neste artigo entende que sustentabilidade e economia caminham juntas, mesmo que não seja este o único aspecto a ser considerado. Evidentemente tem-se consciência de que sustentabilidade envolve muito mais que somente essa parceria, pois ela é usada voltada para a construção em geral, estando também relacionada a aspectos ecológicos que, no entanto, fogem do campo aqui tratado. Entende-se que uma obra ganha sustentabilidade quando gera economia de material e de mão de obra, podendo assim se viabilizar com maior facilidade e propiciar uma qualidade de vida superior para os usuários. Ao se alcançar um resultado que oferece maior qualidade, sendo ao mesmo tempo viável economicamente, acaba-se por conseguir sustentabilidade indiretamente, em maior ou menor escala, nas outras áreas ligadas ao bem estar da sociedade. A restrição feita a essa linha de raciocínio, está diretamente ligada ao fato de que, para se atingir os resultados esperados, não se deve poder usar materiais incorretos em termos de possíveis danos causados à natureza.

Economizar materiais racionalmente, simplificar suas aplicações, viabilizar qualidade de vida para populações carentes, são medidas que, sem dúvida, levam a um uso dos recursos disponíveis de forma mais sustentável. O particular acaba situando-se dentro da questão geral da sustentabilidade.

Ao trabalhar na construção civil com blocos de concreto assentados a seco, algumas economias e facilidades ficam claramente expostas. Dentre elas salientam-se:

11. diminuição do consumo de argamassas, pois elas deixam de ser usadas como revestimentos;

12.eliminação quase total do uso de armações nas paredes, ficando somente seu emprego destinado às vergas; 
13.simplificação e economia de mão de obra com aumento das facilidades para a autoconstrução;

14.uma redução das perdas de materiais, em conseqüência dos fatores citados acima;

15.ganho no tempo de execução. A obra passa a ser mais rápida e simples;

16.maior facilidade para se ter qualidade na obra tendo em vista a simplificação conseguida.

Outro aspecto interessante a ter em conta é aquele relativo à necessidade de se trabalhar com um nível mais elevado de controle qualitativo. O projeto precisa ser elaborado com detalhes do empilhamento das peças. O mesmo se pode dizer em relação às instalações elétricas e hidráulicas. Para diminuir ou até zerar as perdas tudo deve ser previamente pensado. Os blocos de concreto, por si só, não exigem nenhuma tecnologia diferente nem sofisticada, no entanto exigem uma disciplina no uso, que nem sempre é adotada em outros tipos de construção. É dentro dessa filosofia que se consegue o barateamento dos custos na obra.

\section{Considerações Finais sobre a Proposta}

O texto elaborado partiu da premissa, até aqui subentendida, de que as pessoas pobres ou não, têm capacidade para escolher e fazer sua própria casa desde que recebam o suporte necessário, corretamente dimensionado. Uma boa solução pode ser usada com muito pouca ajuda. Trabalhar empregando um produto simples, livre para escolher o que fazer, quando fazer e como fazer. Esta é a idéia. Desta forma se terá qualidade e economia.

O governo de Goiás lançou, em 2001, um programa muito interessante que pode e deve ser analisado quanto aos resultados alcançados até $o$ momento. Por meio de um processo de triagem as pessoas que querem construir ou reformar sua casa recebem parceladamente em cheques (entregues seqüencialmente após cumprimento de etapas construtivas) um determinado valor para comprar materiais no comércio do Estado.
Não se trata de financiamento, mas sim de doação. O comerciante que recebe o cheque o usa exclusivamente para pagamento de ICMS. Dessa forma, atende-se aos mais pobres, que passam a melhorar ou construir sua moradia e aumenta-se eventualmente a arrecadação de ICMS. A idéia é exemplar. Cada pessoa fica com a liberdade de decidir a melhor forma de empregar o recurso. Esse aspecto financeiro poderia se agregar ao sistema descrito até aqui.

O que se oferece neste artigo, no entanto, é apoio tecnológico para o uso de um produto que exige disciplina. No fundo, é o emprego dessa disciplina, mais do que o produto propriamente dito que trará bons resultados.

\section{Referências}

FERREIRA, Paulo Emílio Buarque. Mutirão e autogestão em São Paulo: habitação popular na gestão Erundina. Cadernos de pesquisa do LAP, São Paulo, n.27, 1998.

GALLEGOS, H. Albañileria estructural.. Lima: Fondo Editorial, 1989.

GRASSIOTTO, Junker de Assis. Blocos de concreto assentados a seco: um sistema para autoconstrução. 2000. 296f. Dissertação (Mestrado em Estruturas Ambientais Urbanas) - FAU, Universidade de São Paulo, São Paulo, 2000.

HUTH, S. Construir com celulas tridimensionales. Barcelona: Ed. Gustavo Gili, 1977.

SZUCS, C. P. Autoconstrução: desafio profissional. In: SEMINÁRIONACIONAL SOBREDESENVOLVIMENTO TECNOLÓGICO DOS PRÉ-MOLDADOS E AUTOCONSTRUÇÃO, 1995, São Paulo. Anais... São Paulo: NUTAU, FAU/USP, 1995.

SERRA, G. G. Diffusion of construction technology information: the case of Mãos a Obra. In: SEMINÁRIO INTERNACIONAL SOBRE TECNOLOGIA E DESENVOLVIMENTO, 2000, São Paulo. Anais... São Paulo: NUTAU, FAU/USP, 2000.

TASCHNER, S. P. São Paulo: moradia da pobreza e o redesenho da cidade. In: SAMPAIO, Maria Ruth Amaral de (Coord.). Habitação e Cidade. São Paulo: FAU/USP, 1998. 